\title{
Sebastian Wyss
}

sebastian.wyss@uzh.ch

\section{Does Wittgenstein have a Method? The Challenges of Conant and Schulte}

\section{Abstract}

Does Wittgenstein have a method? There are two challenges to an affirmative answer. One is put forth by Schulte, who claims that Wittgenstein's method is little more than a skill, and thus not a method in any ambitious sense of that word. Another is Conant's view that the philosophy of the later Wittgenstein entertains not one method, but a variety of methods. I tackle these challenges by questioning what I take to be their presupposed conceptions of 'method' and conclude that we can indeed speak of Wittgenstein's method in an interesting sense. Thereby, the concept of method will be elucidated and the sense in which Wittgenstein's philosophy has a method clarified.

\section{Introduction}

Wittgenstein's methodological considerations belong to his most important contributions to philosophy. These considerations suggest that there is a method which informs the work of the later Wittgenstein. That claim, however, has been challenged in two ways. Schulte calls into doubt the idea that the later Wittgenstein had a method in any ambitious sense of the word (2002). For Schulte, Wittgenstein did at best have a method in a non-ambitious 
sense, which is little more than the skill of dealing with philosophical problems. Schulte gives two reasons: The first is that Wittgenstein has not provided an illuminating description of his method at any stage of his thinking. The second is that there is no theory in the framework of Wittgenstein's philosophy, and that methods in some way require theories. Conant maintains that, for the later Wittgenstein, there is not one method, but a multitude of methods (2012). Conant provides two reasons. The first is his reading of PI \$133, which states that "there is not a single philosophical method". The second is his insistence that a plurality of grammars require a plurality of methods. The aim of this essay is exegetical and I will defend three interpretative claims against the challenges of Schulte and Conant. First, Wittgenstein did employ a method that provides general guidelines for practising philosophy; second, he did reflect on his method, which is embodied in his methodological remarks; third, what he takes to be his method does not diverge substantially from his employment of it.

To show what is the issue, let me give a brief description of my interpretation of Wittgenstein's method: Philosophy is concerned with questions of sense, and not with questions of truth. A philosophical problem is a misunderstanding or a lack of understanding of the meaning of some words. ${ }^{1}$ Their meaning is closely connected to the use that relevant speakers make of these words (sometimes, the same sign has a different use for different groups of speakers or even individual speakers). However, the explanations of the meaning of words which a person gives cannot be accepted without further ado; they might incorporate philosophical mistakes and misunderstandings and are the raw material for philosophy. Nevertheless, the use of words provides the basis for deciding whether there is a philosophical problem, a misunderstanding of the grammar of language, and what a correct understanding amounts to. A person can be aware that something

\footnotetext{
${ }^{1}$ This does not imply that all misunderstandings are philosophical problems; let alone that every lack of understanding is a philosophical problem. For instance, many misunderstandings due to phonetic similarities are not philosophical. But in every philosophical investigation, a flaw in the understanding is at issue - be it an actual misunderstanding, or a lack of understanding that is problematised by a prudent person before she has fallen into misunderstanding.
} 
is amiss, resulting in disquietude, or she might be unaware. In the latter case, her use can be problematised by an interlocutor. ${ }^{2}$

The use of words as basis for philosophical investigations is one of five central elements of Wittgenstein's method. The other four are the nature of philosophical problems, what the aim of philosophy is, and the sources of problems as well as the means to resolve them. A philosophical problem is a misunderstanding of the use of words. The aim is to attain complete clarity, that is, a completely clear understanding of the use of the relevant words, in such a way that the initial misunderstanding is resolved. Complete clarity is not the same as comprehensiveness, the idea that all potential problems need to be solved. In that way, philosophy is closely tied to individual persons. We cannot resolve philosophical problems once and for all, but have to deal with a philosophical problem in relation to the person who has it. Moreover, there is a further diagnostically relevant category: the sources of philosophical problems. The diverse means, methods or procedures to dispel the misunderstanding must not only take into account the philosophical problem, but also the sources of the problem. Thus, different means may be employed for the same philosophical problem, if the latter has more than one source.

Some of the sources that Wittgenstein mentions are: the craving for generality (BBB 17), the search for definitions where no definition is possible (PI $\$ 65 \mathrm{f}$ ), being held captive by a picture (PI \$115), the lack of surveyability (PI \$122), the tendency of interpreting a use of a word as a strange process (PI \$196), a diet of too few examples (PI \593), and a misleading surface grammar (PI \$664). Further, once the sources of a problem are singled out, the philosopher may choose the means or methods most appropriate to deal with these sources and with the problem. Some of the means that Wittgenstein employs or recommends are: inventing language games (PI \$2, 48), comparing the grammar of two words (PI \$78) or substituting one form of expression for another (PI $\$ 90$ ) (for a longer list, see section 5).

\footnotetext{
${ }^{2}$ There are, of course, different interpretations, for instance Hilmy (1987), Glock (1991), Baker (2004), Baker / Hacker (2005), Morris (2007), Kuusela (2008) or Horwich (2012).
} 
What is the sense of method used in my affirmation that Wittgenstein has "a method of philosophy"? He has an overarching method. That is a method which guides the invention and the application of particular methods or procedures to particular philosophical problems. A short note on my terminology: Since these particular procedures may also be called "methods", I don't distinguish between methods and procedures but between overarching and problem-oriented methods. (Procedures are problem-oriented methods.) Problem-oriented methods are means for the resolution of particular philosophical problems. The overarching method is a general strategy for how to deal with new problems: Determine what the philosophical problem is by looking at the use that a person makes of words (see whether what she says makes sense), check for sources of the problem and try out some means (without guarantee of success) to reach the aim of complete clarity.

Importantly, the method that I ascribe to Wittgenstein is not foundational. It is not the case that the method is the axiomatic foundation of philosophy, and once we get the method right, all philosophical problems will be resolved in due course. In that case, the method would become an unjustifiable monolith. This is not the role that Wittgenstein accords to his method. For him, questions about method are an integral part of philosophy discussing them is itself nothing else than doing philosophy (cf. PI \$121). Nevertheless, his philosophy and his method are not without presuppositions (cf. Glock 2007: 59). Problems and questions about them are to be treated like any other philosophical question. This implies that Wittgenstein's method is vulnerable to attacks on its presuppositions: If it turns out that meaning has no connection whatsoever to use, his method loses its appeal.

I begin by telling two different stories about the development of Wittgenstein's thought in the 1930s (section 1). Then I consider Schulte's position and state my reasons for not being convinced by it (section 2). In section 3, I trace a strict dichotomy of two kinds of methods as a source for Schulte's refusal to acknowledge that Wittgenstein had a method and provide an alternative taxonomy of methods. Next, I discuss Conant's position and argue against his 
claim that grammars require methods (section 4). Finally, I turn to perhaps the most salient objection to my position: the interpretative challenge which is posed by PI $\$ 133$ (section 5).

\section{Continuity vs. discontinuity}

A prima facie difficulty for interpretations that deny that Wittgenstein had a method (Schulte and Conant) is that from 1930 up to 1938 there are many passages about method in the Nachlass. There are remarks in which he speaks about his method (TS 225: 2, MWL 113), in which he ascribes central importance to it (LWL 21) or in which he, in succinct form, states what his method is: "Methode der Philosophie: Die übersichtliche Darstellung der grammatischen Tatsachen" (BT 414) and "My method throughout is to point out mistakes in language" (AWL 27). There is an obvious line of defence, which both Schulte and Conant take: They claim that Wittgenstein's views about method changed between the early and the late 30s. In a rough sense, we can separate a middle from a later Wittgenstein: The middle Wittgenstein was under the illusion that his way of doing philosophy was guided by one method and ascribed central importance to it. The later Wittgenstein avoided that illusion and, with the exception of (PI \$133), stopped talking about method. Schulte and Conant give different accounts of the illusion. For Schulte, the middle Wittgenstein wrongly compared chemistry with philosophy in respect of method and thus ends up with demands that his method cannot meet (2002: 404-6). Conant, on the other hand, sees a close connection between grammar and method: A plurality of grammatical forms requires a plurality of methods. The middle Wittgenstein's insistence on both a plurality of grammatical forms and on there being one method brings tension into his philosophy (2012: 633). I will comment briefly on two of the most striking passages in the work of the middle Wittgenstein. The first is taken from lecture notes from 1930:

The nimbus of philosophy has been lost. For we now have a method of doing philosophy, and can speak of skilful philosophers. Compare the difference between alchemy and chemistry; chemistry has a method and we can speak of skilful chemists. But once a method has 
been found the opportunities for the expression of personality are correspondingly restricted. (LWL 21)

In this passage, Wittgenstein intimates that philosophy has undergone a great change, brought about by himself, and specifies the difference as one of doing philosophy without a method versus doing philosophy with a method. The introduction of a method in philosophy brings sense to speaking of skilful philosophers. Thereby, the philosophers lose their nimbus; they are only skilfully applying a method, not expressing their personality in their work.

The second passage is from an early version of the preface of the PI. In this version, there is an additional passage which did not make it into the final version:

Ich beginne diese Veröffentlichung mit dem Fragment meines letzten Versuchs, meine philosophischen Gedanken in eine Reihe zu ordnen. Dies Fragment hat vielleicht den Vorzug, verhältnismässig leicht einen Begriff von meiner Methode vermitteln zu können. (TS 225: 2, cited after Schulte 2002)

The fragment to which Wittgenstein refers in this passage could either be the whole body of the text of the Frübfassung (TS 220 \& 221), or the first half of it (TS 220), or a segment of TS 220 (cf. Schulte 2002: 400). The later omission of this passage is relevant to my discussion, because it apparently removes the only allusion to the method from the preface, which, in turn, reduces the occurrence of the word "method" to a few paragraphs of the body of the PI.

Turning the tables, Schulte and Conant now demand an explanation from interpreters who claim that Wittgenstein has a method: Why are such passages absent or even omitted from the PI? Here is my explanation: Broadly speaking, there is a shift from middle Wittgenstein's emphasis on the discovery of the one method to his refraining from emphasising such a discovery later on. This, however, does not mean that the later Wittgenstein does not have a method. I see one main reason for the shift: Wittgenstein's continuous concerns about his own vanity. Proclaiming that one has found "the method of philosophy", that after 2000 years of history, one has finally brought philosophy onto the right path, even if true, is a claim that is easily seen as 
demonstrating vanity. Accordingly, it is replaced by a more humble one: "a method is now demonstrated by examples" (PI \$133; see section 5). Whether this method can sustain the claim that it is the right one depends, among others, on its ability to solve philosophical problems.

More importantly, the shift isn't as substantial as one might think: the later Wittgenstein may have a method without saying that he has one. The possibility exists that the remarks in the Investigations that concern methodology amount to a method. If they fulfil our requirements for being a method, then there is no obstacle to identifying a method in Wittgenstein's later work. That of course depends on the notion of method, which will be discussed in section 3 .

At this stage, both readings have a story that is prima facie plausible. However, the account that Schulte and Conant give of the alleged illusion of which middle Wittgenstein was a victim has to be scrutinised. They think, in their respective versions, that Wittgenstein had good reasons to give up the talk of "the method of philosophy". As I will show below, the reasons that they present are not convincing.

\section{Schulte: "Little more than a skill"}

Schulte's main contention is that the method which plays such an important role for middle Wittgenstein is in fact "little more than the skill itself" (2002: 405), or even that it is "a method basically amounting to a special type of skill" (2002: 406). The core passage to which Schulte alludes is the one cited above (LWL 21). There, Wittgenstein compares two sets of differences: on the one hand the difference between a philosophy that has a method and a philosophy that has none, and on the other the difference between alchemy and chemistry. The way Schulte reads this passage is very peculiar. On the one hand, he takes the cue "skill" from it, in order to claim that Wittgenstein's philosophy has no ambitious method (see below), but that what can be learned from Wittgenstein is a special type of skill. On the other, he claims that in that very passage, Wittgenstein is the victim of a "self-misunderstanding of his method"' (Schulte 2002: 406). 
The picture that Schulte draws is the following: A skill requires a framework for its exercise. For chemistry, the framework includes a theory. Since, for Wittgenstein, philosophy has nothing to do with scientific or quasi-scientific theories, the framework of philosophy does not contain a theory. Rather, it is "at most a kind of tradition, an institution or a common background" (Schulte 2002: 404). Now, at least in the quoted passage, Wittgenstein draws a sharp contrast between traditional philosophy and a new way of doing philosophy (like the contrast between alchemy and chemistry). So there is a new element, which does not belong to tradition, the old institution or the common background. Schulte concedes that "Wittgenstein felt that he had discovered something", and he compares this discovery to the discovery of

a [new] style of painting, a method of playing the violin, or a new form of cuisine. No one will expect you to be able to give an informative account of that sort of style or method [...] His failure to produce anything like a satisfactory account of this method would have made it clear from the beginning that to the extent he really had found a new method it was a method of the second kind, that is, a method basically amounting to a special type of skill. (Schulte 2002: 405)

In effect, Schulte sees a mismatch between middle Wittgenstein's description of his method and his practice: that the latter is not guided by an ambitious method, as the description would have it. ${ }^{3}$

Schulte distinguishes between two kinds of method. Those methods which are a mere skill (or not much more) and those which are (considerably) more than a mere skill. The latter are called "method[s] in an ambitious sense" (Schulte 2002: 406), and the former we may call methods in a non-ambitious sense. Note that it is not per se clear how "method in an ambitious sense" (henceforth "ambitious method") has to be understood. What Schulte does not have in mind are methods with ambitious goals. For Schulte, there may be non-ambitious methods with ambitious goals. If Wittgenstein conceived of his method as one that could be used to resolve all philosophical problems, his goals are certainly

\footnotetext{
${ }^{3}$ Ironically, Dummett saw a similar mismatch in the work of the later Wittgenstein, though in the opposite direction: that his practice includes theses even though his description suggests otherwise (1978: 434, 452).
} 
ambitious. But, according to Schulte, his method is not of the ambitious sort. Thus, "ambitious method" is best understood as being defined as more than a mere skill.

There is an issue concerning the notion of skill as it is used by Schulte. Do skills belong to the qualities of a person? In that case, we could say: "He is generous, arrogant, tall, and has an amazing skill as a sculptor." If so, there is tension with the standard explanation of "method" as a way of doing things (by OED, Macmillan and Merriam-Webster). As such, a method is not a quality of a person, and it becomes questionable how nonambitious methods are methods at all. That is why Schulte's "skill" has to be understood as "craft": An art, profession, occupation or trade that involves a skill. The sentence "The craft of cabinetmaking was much admired in colonial times" refers to a trade or profession, and not to the skill employed in that trade. Then "method in the non-ambitious sense" is compatible with the above notion of method: Do it in the way of goldsmiths, or cabinetmakers, or philosophers.

What does it mean for a method to be a mere skill, to be a nonambitious type of method? Based on the picture above, we can isolate two features. (i) The application of non-ambitious methods is not connected to a theory. (ii) Non-ambitious methods do not require an illuminating description to be taught and passed on. Accordingly, in Schulte's picture, we find two arguments why middle Wittgenstein was wrong in thinking that he had a method in an ambitious sense, and why the later Wittgenstein does not have such a method:

I) Wittgenstein's philosophy doesn't have a theory in its framework, therefore it has no method in the ambitious sense in its framework.

II) Wittgenstein didn't give an informative account of his method, therefore he has no method in the ambitious sense.

Ad I: With which sense of theory does this argument work? Following Hanfling (2004), two senses of "theory" might be relevant here. The first are causal-hypothetical theories, as they are common in empirical sciences, such as the postulation of an unobserved body which explains the movement of visible planets 
and comets. If Schulte uses "theory" in that sense, then all nonnaturalistic philosophy is excluded from having a method or methodology. That, of course, would be a harsh consequence. The second sense might be called quasi-scientific. Unlike the first kind, such theories do not offer causal explanations. Similar to it, they try to explain (in a non-causal sense) phenomena by postulating "entities or processes that do not lie open to view" (Hanfling 2004: 189). In this second sense, Schulte's requirement is tailor-made to exclude Wittgenstein's philosophy from having a method. Postulate hidden entities or you will have no theory and therefore no method. But then, Schulte's requirement for an ambitious method to have a theory is itself problematic. Wittgenstein's method is excluded from being a method on the grounds of one of its own features: its special status regarding theories.

Ad II: I take it that the alleged absence of an illuminating description is not sufficient proof that a particular method is of the non-ambitious kind. Rather, it is circumstantial evidence to that effect. Accordingly, there can be an illuminating description of a particular method even if the method is non-ambitious. I disagree because the required circumstantial evidence is missing. In my opinion, Wittgenstein's reflections on his method are of great interest and constitute an illuminating description. To sketch my reasons: In the Investigations, there are many remarks that contain informative descriptions of Wittgenstein's method, most prominently in the so called "philosophy chapter" (PI \89-133), as well as in solitary remarks such as PI $\iint 52,254-255,309,314,340$, $371,387,464,599$, and 664. Indeed, these passages are difficult to interpret due to the "nature of the investigation" (PI pref.), Wittgenstein's laconic predilections and the different voices of the work make it difficult to read. But for instance in PI $\iint 89$ and 90, he provides a sketch of the kind of investigation a philosophical investigation is. It neither studies facts of nature nor causal connections, but is a grammatical investigation that studies "the kinds of statement that we make about phenomena" (PI \$90). Granted, some concepts require clarification. For instance, what is "everyday use" (PI \$116)? But this shows only that Wittgenstein has not resolved every philosophical problem connected with his 
method, not that he has not given an illuminating description of it in any sense. The framework that Wittgenstein provides with the description of his method is not "at most a kind of tradition, an institution or a common background" (Schulte 2002: 405), but an account of the nature of the philosophical problems and their solution.

\section{Remarks on the concept of method}

One source of Schulte's denial that Wittgenstein had a method is that Schulte retains a strict dichotomy between two kinds of method. The first kind is a method that is basically a special type of skill (and thus a "method" in scare quotes). The only alternative Schulte mentions is a method which consists of "rules [...] that spell out what a player should in certain situations do in order to win" (Schulte 2002: 403). Schulte's category of rules conductive to winning should be construed broadly: A physiotherapist does not win against his patient, but he can successfully ease the other's pain. And there might be rules for him to do so. In the case of philosophy, Schulte envisages rules like:

1. If your opponent believes in substances, you are well-advised to begin by pointing out to him that not all nouns function according to the pattern exemplified by labels that may be stuck onto the objects they fit. (Schulte 2002: 403)

That is, Schulte demands from an ambitious method in philosophy that it has explicit instructions for particular cases. For all of them? For many? For just a few? Anyhow, the Investigations doesn't supply such explicit if-then rules. Then, according to Schulte's dichotomy, there remains only one kind of method which could be ascribed to Wittgenstein: a method as a skill. Perhaps one can restate Schulte's two kinds of methods in terms of rules. This restatement exceeds the literal phrasing in Schulte's paper, but may be helpful in presenting a related view: An ambitious method should consist of a comprehensive set of rules that can be applied to any particular philosophical problem. A non-ambitious method would typically be taught by engaging with particular cases, whereby at best some such particular rules may be mentioned (although the particular philosophical investigations could be conducted without invoking 
any rules). I disagree with that picture. To begin with, the requirement of comprehensiveness, which is in force only for the ambitious kind of method, differs depending on whether the set of philosophical problems is logically fixed or open. In the first case, a list of particular rules could be comprehensive. However, it is not clear that any participant of the debate would like to claim that the number of philosophical problems is fixed. In the second case, comprehensiveness can only be achieved if the rules do not apply to particular philosophical problems, but merely give more general guidance. This brings me to the disagreement: Rules of a method don't need to be applicable to particular cases. On the contrary, they can apply to classes of cases, or even to all relevant cases. The rules that I will mention at the end of this section are of this kind. That philosophical problems are to be solved by studying the use of words is such a general rule. Moreover, once general, methodological rules are acknowledged, a method can achieve comprehensiveness not by solving every problem in advance, but by providing rules that outline a way for solving every problem (that is to be solved by that method). In what sense of "method" does Wittgenstein have a method? As an alternative to Schulte's two kinds of methods, we can distinguish methods according to three cross-cutting distinctions: sequential and non-sequential arrangement of rules; creative and mechanic application of rules; overarching and problem-oriented methods. Here are some definitions:

Sequential method: has an ordered and finite set of rules.

Non-sequential method: its rules are not ordered into a series or it has an unlimited number of rules.

Creative application of rules: there is leeway in the application of rules.

Mechanic application of rules: rules are applied without (much) leeway.

Overarching method: used to create methods that deal with problems.

Problem-oriented method: used to deal with problems. 
I will consider a few examples which combine these features in various ways. First, the method of picking a lock by using a bump key: Insert the bump key and pull it back until you notice a click. Then, turn the key in the right direction while hitting it with a special hammer. Repeat until the lock opens. Of course, in order to follow this quick method you need to have the right instruments, and you need to practice. Nevertheless, once you have learned, you can mechanically apply the steps in the right order (sequential) and you will be able to open many locks (problem-oriented). Some other examples of methods with the same features are a method of folding a t-shirt in two seconds, a method of projecting a geometrical figure and a particular method of salary negotiation the main point of which is to avoid naming a number. Since these methods are both mechanical and sequential, we could call them algorithmic methods. These are not algorithms since they operate not exclusively with signs or functions. (Turing machines would have a hard time tying a knot.) But analogously to algorithms, they can solve a given range of problems by applying a finite set of mechanically applicable rules.

Second, formal logic provides a method of checking arguments for their validity (problem-oriented). Part of this method is to formalise arguments of natural language. Normally, when we do that we don't try any proposed translation blindly but go with the most plausible one, only to change it later if trouble comes up. That is, the rules of translation are not ordered in a sequence (nonsequential). (It's an open question whether one could construct an algorithm which performs these tasks.) It's creative, since the choice of formalisation depends on our latitude of judgement.

Third, take Descartes' method in his Discours de la Méthode (2011: 33). It consists only of four rules that are to guide human understanding in all its endeavours. One could argue that the rules are ordered in a sequence: First, get rid of all supposed truths if there remains some doubt. Second, divide the problems into subproblems. Third, start with those problems that are easy to solve. Fourth, strive for completeness in your enumeration of knowledge. These rules are to be applied creatively. For instance, we have to judge ourselves where to carve out the sub-problems. 
Finally, while the method does not call explicitly for the creation of problem-oriented methods, the extreme generality of the method implies that some further methods need to be applied, for instance to check whether a supposed knowledge is free from any doubt. Thus, Descartes' method seems to be overarching.

Fourth, there is a method of dog training called "dog whispering". Instead of viewing the relationship between owner and dog as one of issuing commands and following them, it sees it as one of mutual understanding, and thereby sets the goal for dog training. Consequently, what is perceived as a problem is not only the behaviour of the dog who chews on the cushions while the owner is absent, but also the behaviour of the owner who comes home, gets angry, swears in a raised voice at the dog and then misinterprets the ensuing fear of the dog as guilt. A means to resolve such problematic behaviour, then, is to both change the behaviour of the dog through conditioning and the behaviour of the owner through explanation. Naturally, these guidelines alone cannot teach one to be a skilful dog whisperer. But they provide guide rails to integrate solutions of particular problems into a wider framework, adapt existing procedures to new cases or even invent new procedures. Thus, this method is overarching, non-sequential and creative.

Any method must delimit the range of problems it deals with and state what counts as a solution. For some methods, this can be done very easily. The problems of the bump-key method are locked doors (and other locked things) and the solution of the problem consists in an unlocked and open door. For logic, the problems are obvious: arguments. But the solution is less clear-cut than an open door - has the argument been misrepresented or is it really not valid? The range of Descartes' method is less general than it first appears: it is limited to knowledge. And rule one states what amounts to a solution: no reason for doubt is left.

Many rules of the methods mentioned above state what has to be done in order to succeed, in order to reach a given goal: they are regulative. These rules are also constitutive in a certain aspect: They determine what counts as following the method $m$. Nevertheless, such rules normally do not determine what counts as an activity for 
which they provide guidance. For instance, the rules of the angling method of fishing do not determine what fishing is. In this respect, Wittgenstein's method is a special case, because it is strongly linked to a conception of philosophy. For instance, the rules that state the aim and the problems of the method determine the goal, instead of giving guidance how to reach the goal. They are therefore constitutive. But constitutive rules can be action-guiding, too. If there is a mismatch between the goal as we pursue it in practice and our real need, a change of the pursued aim in our practice is crucial to achieve what we really need to achieve. The belief that it is a constitutive rule of chess that the queen can only be moved while the player stands on his head might prevent some players from moving the queen. Likewise, a difference in the conception of philosophy corresponds to a difference in how the subject is pursued, for instance in the role that is ascribed to scientific discoveries. If there are good reasons for or against one of the conceptions or methods, then this discussion is of obvious importance. Thus we can see how the five elements which I identified in Wittgenstein's method are action-guiding. The rules that determine the nature of problems and aims are important to pursue aims that address our real need (cf. PI \$108). But what are the rules of Wittgenstein's method? Here is a very inadequate attempt to press the five elements I have mentioned into rules. They are at a high level of abstraction and would require further elucidation.

R1) A philosophical problem is a misunderstanding or a lack of understanding of our use of words.

R2) The aim of philosophy is to attain a completely clear understanding of the use of those words that are problematic.

R3) What counts as a misunderstanding and what counts as an understanding is to be determined by studying our use of words.

R4) One philosophical problem may have different sources.

R5) A variety of methods have to be applied depending on the problem, its sources and the other problems that an individual has. 


\section{Conant: "Methods, not a method"}

Conant claims that for the later Wittgenstein, there is not one method, but a multitude of methods. Obviously, this alludes to the last and boxed sentence of PI $\$ 133$ (Conant 2012: 635). I will discuss the interpretative challenge of this sentence in the next section. Conant provides an intricate story of the development of Wittgenstein's thought from early to middle to later Wittgenstein in terms of method and grammar. Moreover, Conant is of the opinion that these two, grammar and method, are linked in an important way. One can put it succinctly: grammars require methods. The general story is that early Wittgenstein held that there is one method of philosophy and that there is a fixed number of possible forms of grammar. Middle Wittgenstein realised that the possible forms of grammar are not fixed, but clung to the idea that there was one method. Later Wittgenstein then realised that the idea of one method is undermined by there being an unlimited variety of forms of grammar, and consequently abandoned the idea that he had one method (Conant 2012: 640, 642). I will point out some gaps in the story. But let's first see how Conant puts it:

One might formulate the negative aspect of the insight which underlies the shift here in question as follows: the relinquishing of the first of these definite articles (the logic of our language) requires the correlative abandonment of the second of these definite articles (the method of philosophy). One can also formulate the point here at issue in more positive terms as follows: an open-ended, infinitely extendable conception of a family of possible forms of grammar comes to be seen to require a correlatively open-ended, infinitely extendable conception of a family of possible forms of philosophical method. That the one requires the other, however, takes time and work for Middle Wittgenstein to come to appreciate. (Conant 2012: 640-1)

Some elucidations are in order. First, what does "open-ended, infinitely extendable" mean? I understand this as alluding to a potential infinity: On the one hand, it is obviously not the case that we have an infinite number of elements at hand. On the other hand, the set of elements is unlimited in the sense that we can always find a new element. The antonym of it is "limited": At a given point, we have written down all elements of the set. This 
point may have not been reached yet, but it is in principle attainable. Consequently, Conant does not contrast one method with a plurality of methods, but with an unlimited plurality. Second, what are "forms of grammar"? I take them to be equivalent to "grammatical forms". Of course, early Wittgenstein did not talk about "grammar", but about "logic". Thus, are we actually comparing "logical forms" of early Wittgenstein with "grammatical forms" of middle and later Wittgenstein?

How can the shift away from the logic towards a plurality of logics (or grammars) be understood? A false start would be to say that the Tractatus would advocate a limited number of logical forms which middle Wittgenstein replaced by an unlimited number of grammatical forms. The problem is that this is not true of the Tractatus: For one thing, there is an important distinction between logic and the application of logic (TLP 5.557). Only the latter decides which elementary propositions there are, and with that, which logical forms there are. Logic does not decide whether there is a 27-termed relation (TLP 5.5541). For another, the "logical forms are without number" (TLP 4.128). That is, in the Tractatus, the logical forms are unlimited, too.

A better way to tell Conant's story takes into account the distinction between three different levels in the Tractatus: On the first level is the general form of a proposition. All propositions with a sense conform to this one form: they are truth-functions of elementary propositions. To deny this yields an alternative position like (i) that there are more than one general logical forms, but still a limited number (one could call them "categories"), or (ii) that there is an unlimited number of general logical forms. Since on this second alternative, the distinction between general grammatical forms and grammatical forms becomes doubtful, on that account, the first level collapses into the second. The second level comprises the logical forms: proper names, predicates, 2-termed relations, 27termed relations. Thus, ignoring depth analysis, "is a boy" and "is a man" have the same logical form, but not "is an uncle". For the latter is a disguised relation. The third level is then the logical form of a specific sentence which in the terminology of the Tractatus, is called the "logical structure". 
For Conant, the contrast between the early notion of logic and the later notion of grammar is pertinent; that is, the move from logic to grammars. So here is my take on Conant's story. Middle Wittgenstein abandoned the idea that all propositions conform to one form, the general form of a proposition. But he retained the other two levels in modified form. Instead of logical forms we have now grammatical forms, which also include differences such as between "has a key" and "has a pain". Thus, there is indeed an important change in terms of grammar or logic: the early Wittgenstein thought that there is one logic of language, which is topic-neutral, and can be used to talk about any topic. Middle Wittgenstein, however, realised that the grammar of language can take very different general forms in different language games. The story now explains that the one general logical form corresponded to one method, but that this monism of method had to be given up once the monism of general propositional form had been given up.

Third, what are "forms of method"? Perhaps we can understand this expression by analogy with "forms of grammar". A form of grammar is what is common to several sentence-types. For instance, "Romeo loves Juliet" and "Peter beats Paul" have the same form (in one respect) as in both sentences, a two-termed relation occurs. Analogously, in the piecemeal processes of tackling confusions of two persons, what is common to two applications of method is a form of method. For instance, one philosophical move is to point to a difference of symbol of two signs that appear to be similar (cf. Conant 2012: 630, TLP 3.23). That is, forms of method turn out to be nothing else than methods in what I call the problemoriented sense. Thus, the substitution method and the elimination method for solving mathematical equations are two methods, or two forms of method.

The story rests on an insight on Wittgenstein's part. This insight can be presented in the form of an argument: 
2) In philosophy, an unlimited number of general forms of grammar requires an unlimited number of methods. (Grammars require methods. $)^{4}$

3) The number of general forms of grammar of our language is unlimited.

4) Hence, philosophy requires an unlimited number of methods.

Middle Wittgenstein realises (3) contra early Wittgenstein, but fails to grasp (2). Only the later Wittgenstein makes the next step and reaches the conclusion (4). The argument is a valid modus ponens, but I see two problems with it.

On a preliminary note, it would be uncharitable to read this argument as excluding any approach to philosophy which does not accord a central role to forms of grammar or logic (Kant, Husserl, Descartes) from having a method at all. After all, Conant's formulations are directed at Wittgenstein's development, not at the history of philosophy in general. Moreover, he could react by generalising premise (2) to any "object or medium of philosophical investigation (logic/grammar)" (Conant 2012: 640). That is, if the object of philosophical investigation sports an unlimited number of forms, then an unlimited number of methods is required to deal with them.

The first problem is the main premise (2). Conant is clearly committed to something like this by his story and the long quote above. But why should we accept anything like that? For one thing, there is no indication that Wittgenstein thought that a particular grammatical form must be investigated by a particular method. The methods that early and later Wittgenstein provide are not grammardependent. For the Tractatus, two methods come to mind: first, the method of constructing an ideal notation (cf. TLP 3.325, 4.1121), and second, the method of using this ideal notation to demonstrate that certain sentences are nonsensical, and to understand other sentences clearly (TLP 4.112, 6.53). Perhaps one could argue that Wittgenstein's ideal notation requires a general propositional form.

\footnotetext{
${ }^{4}$ In other words: If our language has an unlimited number of general forms of grammar, then philosophy should have an unlimited number of methods.
} 
Accordingly, the methods of the Tractatus would depend on it. Even if so, this shows only that the Tractarian methods have to be discarded together with the general propositional form. It does not show anything about the methods of the Investigations, especially not that there is an unlimited number of them.

What about the Investigations? If Conant is right, methods that deal with a particular form of grammar should be all over the place. Some of the means that Wittgenstein employs are: inventing language games (PI $₫ 2,48$ ), looking how a word is taught (PI $₫ 9$, 35 , 179), comparing the grammar of two words (PI \$78), substituting one form of expression for another (PI \$90), a surveyable representation (PI \$122), ${ }^{5}$ imagining different general facts of nature (PI \$142, PPF \$366), showing something about the grammar of one word by connecting it to the grammar of another (PI \$492) and looking at different contexts of the use of a word (PI \$593). In my opinion, none of these procedures or methods are grammar-dependent. Some of descriptions of them directly use the word "grammar" - but, of course, comparing the grammar of two words in no way restricts this procedure to any particular form of grammar.

Moreover, that some methods may be applied to different forms of grammar is especially virulent for methods that deal with the obstacles of a proper understanding, with the sources of confusions. For instance, in the Big Typescript (BT 406), Wittgenstein claims that philosophical problems are not difficult for the intellect, but for the will. This requires strategies or methods to outwit the will: we have to fight certain intellectual temptations, tendencies. Similarly, an important obstacle to properly understand that part of grammar that causes trouble are ideals, pictures of how it must be which have settled in the mind. Just to present a clear view of the relevant grammar may here not achieve the desired

\footnotetext{
${ }^{5}$ There are different ways to interpret "surveyable representation" in the Investigations. Kuusela sees it as a sort of umbrella term for all methods that Wittgenstein uses (Kuusela 2008: 269). Glock favours a more specific interpretation (Glock 1996: 280). I tend towards a specific interpretation different from Glock's. But this matter need not be decided here. Regardless of interpretation, surveyable representations are an important means that Wittgenstein advocates.
} 
effect. The ideal has to be tackled separately, for instance by constructing a simple language game as in (PI $\$ 2,48)$. That is, there are many procedures that are grammar-independent. But then, even if Conant were right in claiming that the later Wittgenstein rejected the idea of the early and middle Wittgenstein that philosophy had one method, that he did so in virtue of abandoning the view of the grammar is highly implausible. For the relation between grammars and methods is much too feeble to sustain such a major change.

The second problem concerns the claim that an unlimited number of methods is incompatible with there being one method. Initially, this seems plausible, since we have to understand the latter claim as there being at most one method. Explaining away the tension is essentially the same as dealing with the interpretative challenge of the last and boxed sentence of (PI \$133). I will address this in the next section.

\section{5. "Method" in the Investigations}

In what way does the term "method" occur in the Investigations? Concerning method, we can distinguish three levels. On the first, there is an overarching method that guides the creation of new problem-oriented methods: This is the one of which I gave a short five-rule description in section 3. On the second level, there are various problem-oriented methods such as imagining a language that would fit a particular philosophical theory or picture (and others mentioned in the last section). The third level comprises applications of problem-oriented methods; that is the methods used in actual or exemplary philosophical investigations. Here, it is important to keep in mind that philosophy treats problems of understanding. And it is individual persons who misunderstand the use of words. That is, this level consists in addressing the confusions of particular persons; the means or methods applied need to take into consideration the sources of the problems and the other problems the person has.

The word "method" does only occur in a few remarks in the Investigations. One use concerns the connection between sign or picture and meaning, and whether there is a method of projection to get from one to the other (PI \$139, 141, 366, 548). Another use 
is as a method of measurement (PI \$242). Both don't deal with the sense of "method" that interests us. Closer to our interest are two remarks that concern a problem-oriented method. (PI \$48) mentions "the method of $\$ 2$ ", and applies it to a new case. The method, in this case, is to consider a language game where an antecedent description of language as a whole is indeed correct. The point of studying "the phenomena of language in primitive kinds of use in which one can clearly survey the purpose and functioning of words," is to "disperse[...] the fog" which has been brought about by a "general concept of meaning" (PI \5). That is, it is a method or procedure that is destined not to tackle a particular form of grammar, but a grammar-independent hindrance for taking the grammar of language for what it actually is: diverse. This is important insofar as it shows that Wittgenstein used "method" in a sense which presupposes that there are several methods. But this of course does not rule out the possibility that he used that word in another sense, too. The most pertinent remark about method is PI \$133, which would merit a discussion of its own. For the sake of brevity, I will only examine the two occurrences of that word.

Sondern es wird nun an Beispielen eine Methode gezeigt und die Reihe dieser Beispiele kann man abbrechen. (PI \$133)

"Examples" is written in plural, "method" in singular. Is this the last surviving reference to Wittgenstein's one method? Or is he talking about one of many methods? If "eine" were in italics, the former reading should be favoured. But since it is not, both readings can be upheld. I lean towards the former, since it chimes with my over-all reading. Instead of laying the foundations of philosophy, what we get from the later Wittgenstein are a bunch of examples of philosophical problems plus their resolutions. In these philosophical investigations, a method has been at work, and, Wittgenstein insinuates, the method can be learned by considering the examples. Importantly, however, "showing the method" does not exclude making methodological remarks, of which (PI \$133) itself is a prime example.

Es gibt nicht eine Methode der Philosophie, wohl aber gibt es Methoden, gleichsam verschiedene Therapien. (PI \$133) 
Here, it seems that Wittgenstein explicitly denies that philosophy has one method. My response to this is that in the Investigations, it is crucial to notice deliberate ambiguities, such as that of "being hidden" (PI \$91, 126 vs. \$129) or the use of one word in positive and negative contexts, e.g. "essence" (PI \89, 371 vs. $\$ 92,97,113$, 116). Likewise, there is a deliberate ambiguity between the method that is "demonstrated by examples" (PI \$133) and the insistence that there are many methods (PI \$133). The first is about the overarching method, which provides a general strategy to tackle philosophical confusions and an understanding of the nature of philosophical investigations. The second is about is about the variety of procedures, means or problem-oriented methods that the method enables to create or apply. While Wittgenstein did not draw this distinction himself, he is committed to it. The reason for this is that it removes the tension to the passage in the preface where he talks about the "nature of the investigation". Thus, the sentence in the box attacks the misconception that the talk of "a method" implies that there is one fixed procedure which one can follow - the method consists, on the contrary, of applying and creating a variety of problem-oriented methods. It is poly-procedural.

The claim that Wittgenstein in the Investigations held that he had a method to teach is supported by a passage from the preface. While, indeed, the word "method" has vanished completely from the final version of the preface, there is a remark about the "nature of the investigation":

Und dies hing freilich mit der Natur der Untersuchung zusammen. Sie nämlich zwingt uns, ein weites Gedankengebiet, kreuz und quer, nach allen Richtungen hin zu durchreisen. [...] So ist dieses Buch eigentlich nur ein Album [von Landschaftsskizzen]. (PI pref.)

And the sense of "nature of investigation" is not a lightweight one. For it has direct repercussions for how one can go about the investigation. There is no natural, antecedently established order which a presentation of Wittgenstein's philosophy could follow. Rather, those philosophical confusions and problems that are in force in our dialogue partner or in ourselves need to be tackled. Moreover, treatment of the problems leads to "long and meandering journeys" ("langen und verwickelten Fahrten") (PI 
pref.). "Verwickelt" carries with it the idea that the problems are interconnected, and the relations between them weave a chaotic and asymmetrical net. Several strands of connection go out for instance from the referential doctrine of meaning, which can stand at the beginning of many philosophical problems - disregard for language use, or the idea of mental entities.

Now, we can go back to the question of continuity or discontinuity between a middle Wittgenstein who explicitly claimed to have found a method and the later Wittgenstein who does not talk much about method. As we have seen, the reasons that Schulte and Conant put forth to explain why Wittgenstein had to change his opinion turn out to be weak. But then, there is no good story of discontinuity. Thus, the only plausible story we have is one of continuity: The later Wittgenstein became more cautious in advertising his method as a central element of his philosophy, but continued to reflect on and describe his method. In sum, there is good evidence that the later Wittgenstein had a method in an ambitious sense, one which which he tried to pass on through his samples of philosophical investigations and the methodological remarks that accompany them.

\section{Conclusion}

Schulte's claim that Wittgenstein's method is little more than a skill in effect states that no method can be ascribed to the middle and later Wittgensteins. But Wittgenstein's remarks on how to pursue philosophy constitute just that: a method. The philosophical importance of Wittgenstein's work is not exhausted by his contributions to particular areas of philosophy such as philosophy of mind, language or mathematics, nor by the alleged exemplary status of his philosophical investigations. His reflections on how to engage with philosophical problems are a contribution to philosophical method with which contemporary philosophers can profitably and critically engage. Moreover, Schulte's two requirements for a method are problematic. The first one, that methods are connected to theories, excludes Wittgenstein's method from being a method in virtue of one of its own features qua method. The other requirement is reasonable, but fulfilled: the 
claim that Wittgenstein does not provide an informative description is unconvincing. The comparison of the philosophical method with a way to play the violin leaves the method as something magical, which is only acceptable if we are not ourselves to play the violin.

Conant is quite right to stress the diversity of methods in the Philosophical Investigations. However, the distinction between overarching and problem-oriented methods paves the way for having the cake and eating it. The overarching method, which is the subject of methodological discussions, guides the invention and application of the various problem-oriented methods. Moreover, the idea that methods are closely tied to general grammatical forms is misguided. Not a single method which I have come across in Wittgenstein's writings is directed at a particular form of grammar. Conant, however, needs a whole batch of them to validate his claim that there is an important connection between methods and grammatical forms.

What remains is the enormous groundwork of digging up and specifying the various methods used by Wittgenstein in the course of doing philosophy. Since this cannot be done without engaging with the particular philosophical topics to which these methods are applied, it is truly a great task. Moreover, the distinction between problem-oriented and overarching methods could be applied to the Tractatus, too. Thus one could try to describe the method of the Tractatus independently of the one procedure of (6.53). Perhaps a discussion of the second method of the Tractatus $(3.325,4.1121)$ of studying ordinary language under the aspect of an ideal notation could bring to the fore the fundamental division between setting up the ideal notation and applying it.

\section{References}

Baker, G.P., 2004. Wittgenstein's Method. Neglected Aspects. ed. by K. Morris. Malden: Blackwell.

Baker, G.P. and Hacker, P.M.S. 2005. "Philosophy". In: G.P. Baker and P.M.S. Hacker, ed. 2005. Wittgenstein: Understanding and Meaning. Volume 
1 of An Analytical Commentary on the Philosophical Investigations. Part I: Essays. Oxford: Blackwell. Second Edition.

Conant, J. 2012. "Wittgenstein's Methods". In: O. Kuusela and M. McGinn, ed. 2012. Oxford Handbook of Wittgenstein. Oxford: Oxford University Press, pp. 620-645.

Descartes, R. 2011. Discours de la Méthode. ed. and trans. by C. Wohlers. Hamburg: Meiner.

Dummett, M. 1978. Truth and other Enigmas. Cambridge: Harvard University Press.

Glock, H.-J. 1991. "Philosophical Investigations Section 128: 'Theses in Philosophy' and Undogmatic Procedure". In: R.L. Arrington and H.-J. Glock, ed. 1991. Wittgenstein's Philosophical Investigations. London: Routledge, pp. 69-88.

Glock, H.-J. 1996. A Wittgenstein Dictionary. Malden: Blackwell.

Glock, H.-J. 2007. "Perspectives on Wittgenstein: An Intermittently Opinionated Survey". In: G. Kahane, E. Kanterian and O. Kuusela, ed. 2007. Wittgenstein and His Interpreters. Essays in the Memory of Gordon Baker. Malden: Blackwell, pp. 37-65.

Hanfling, O. 2004. "The Use of 'Theory' in Philosophy”. In: E. Ammereller and E. Fischer, ed. 2004. Wittgenstein at Work: Method in the Philosophical Investigations. London: Routledge, pp. 183-200.

Hilmy, S. 1987. The Later Wittgenstein. The Emergence of a New Pbilosophical Method. Oxford: Blackwell.

Horwich, P. 2012. Wittgenstein's Metaphilosophy. Oxford: Clarendon Press. Kuusela, O. 2008. The Struggle Against Dogmatism. Wittgenstein and the Concept of Philosophy. Cambridge MA: Harvard University Press.

Moore, G.E. 1993. "Wittgenstein's Lectures in 1930-33”. In: J. Klagge and A. Nordmann, ed. 1993. Philosophical Occasions. Indianapolis: Hackett, pp. 46-114.

Morris, K. 2007. "Wittgenstein's Method: Ridding People of Philosophical Prejudices". In: G. Kahane, E. Kanterian and O. Kuusela, ed. 2007. Wittgenstein and His Interpreters. Essays in the Memory of Gordon Baker. Malden: Blackwell, pp. 68-89.

Schulte, J. 2002. "Wittgenstein's 'Method". In: R. Haller and K. Puhl, ed. 2002. Wittgenstein und die Zukunft der Philosophie. Eine Neubewertung nach 50 Jahren. Wien: ÖVB HTP, pp. 399-410.

Wittgenstein, L. 1958. The Blue and Brown Books. ed. by R. Rhees. New York: Harper.

Wittgenstein, L. 1961. Tractatus Logico-Philosophicus. Trans. by B. McGuiness and D. Pears. London: Routledge.

Wittgenstein, L. 1979. Wittgenstein's Lectures. Cambridge 1932-1935. From the Notes of Alice Ambrose and Margaret MacDonald. ed. by A. Ambrose. Oxford: Blackwell. 
Wittgenstein, L. 1980. Wittgenstein's Lectures. Cambridge 1930-1932. From the Notes of John King and Desmond Lee. ed. by J. King and D. Lee. Totowa: Chicago University Press.

Wittgenstein, L. 2009. Philosophische Untersuchungen = Philosophical Investigations. Trans. by G.E.M. Anscombe, P.M.S. Hacker and J. Schulte. ed. by P.M.S. Hacker and J. Schulte. Chichester: Wiley-Blackwell. Fourth Edition.

Wittgenstein, L. 2009. "Philosophie der Psychologie - Ein Fragment $=$ Philosophy of Psychology - A Fragment". Trans. by G.E.M. Anscombe, P.M.S. Hacker and J. Schulte. In: P.M.S. Hacker and J. Schulte, ed. 2009. Philosophische Untersuchungen = Philosophical Investigations. Chichester: Wiley-Blackwell. Fourth Edition, pp. 182-243. Wittgenstein, L. 2013. The Big Typescript. TS 213. ed. by C.G. Luckhardt and M.A.E. Aue. Malden: Wiley-Blackwell.

\section{Biographical Note}

Sebastian Wyss lives in Zurich. He writes his dissertation on methodology and vagueness under the supervision of Hanjo Glock and Hanoch Ben-Yami. 